\title{
Neck circumference and other clinical features in the diagnosis of the obstructive sleep apnoea syndrome
}

\author{
Robert J O Davies, Nabeel J Ali, John R Stradling
}

\begin{abstract}
Background Neck circumference has been suggested to be more predictive of obstructive sleep apnoea than general obesity, but the statistical validity of this conclusion has been questioned. Combining neck circumference with other signs and symptoms may allow the clinical diagnosis or exclusion of sleep apnoea to be made with reasonable confidence. This study examines these issues.

Methods One hundred and fifty patients referred to a sleep clinic for investigation of sleep related breathing disorders completed a questionnaire covering daytime sleepiness, snoring, driving, and nasal disease. Body mass index and neck circumference corrected for height were measured and obstructive sleep apnoea severity was quantified as number of dips in arterial oxygen saturation $\left(\mathrm{SaO}_{2}\right)$ of more than $4 \%$ per hour of polysomnography. Multiple linear regression was used retrospectively to identify independent predictors of $\mathrm{SaO}_{2}$ dip rate, and the model derived was then prospectively tested in a further 85 subjects.
\end{abstract}

Results The retrospective analysis showed that the question "Do you fall asleep during the day, particularly when not busy?" was the best questionnaire predictor of variance in the $\mathrm{SaO}_{2}$ dip rate $\left(r^{2}=0.13\right)$; no other question improved this correlation. This analysis also showed that neither body mass index nor any of the questionnaire variables improved the amount of variance explained by height corrected neck circumference alone $\left(\mathbf{r}^{2}=0.35\right)$. A statistically similar prospective analysis confirmed this relationship $\left(r^{2}=0 \cdot 38\right)$.

Conclusions Prospective study of these patients referred to a sleep clinic with symptoms suggesting sleep apnoea shows that neck circumference corrected for

Table 1 Characteristics of the study populations

\begin{tabular}{|c|c|c|c|c|}
\hline & \multicolumn{2}{|c|}{ Retrospective group } & \multicolumn{2}{|c|}{ Prospective group } \\
\hline & Median & $95 \%$ range & Median & $95 \%$ range \\
\hline $\begin{array}{l}\text { Age } \\
\text { Body mass index }\left(\mathrm{kg} / \mathrm{m}^{2}\right) \\
\text { Neck circumference (in) } \\
\text { Height }(\mathrm{m}) \\
\text { No of }>4 \% \mathrm{SaO}_{2} \mathrm{dips} / \mathrm{h}\end{array}$ & $\begin{array}{l}50 \\
27 \cdot 4 \\
16 \cdot 0 \\
1 \cdot 74 \\
3 \cdot 6\end{array}$ & $\begin{array}{c}33-67 \\
22-42 \\
14-19 \\
1 \cdot 6-1 \cdot 9 \\
0-54\end{array}$ & $\begin{array}{l}49 \\
28 \cdot 0 \\
16 \cdot 2 \\
1 \cdot 74 \\
4\end{array}$ & $\begin{array}{c}27-65 \\
23-42 \\
14-19 \\
1 \cdot 6-1 \cdot 9 \\
0-51\end{array}$ \\
\hline
\end{tabular}

$\mathrm{SaO}_{2}$-arterial oxygen saturation; 1 in $=2.54 \mathrm{~cm}$. height is more useful as a predictor of obstructive sleep apnoea than general obesity. None of the questionnaire variables examined add to its predictive power, but alone it is inadequate to avoid the need for sleep studies to diagnose this disease.

Severe obstructive sleep apnoea affects approximately one in 300 British men. ${ }^{1}$ Its dominant symptom, daytime sleepiness, substantially reduces quality of life ${ }^{2}$ and impairs tasks that require sustained vigilance-particularly driving. ${ }^{34}$ In advanced cases the diagnosis is relatively easy, but identification of less classical presentations is more difficult and requires sleep studies. ${ }^{5}$ In the general population a history of snoring (partial pharyngeal obstruction) and daytime somnolence are useful markers of obstructive sleep apnoea. ${ }^{2}$ In hospital practice, however, sleep studies are the mainstay of diagnosis. ${ }^{5}$ An increased neck circumference (corrected for height) has been suggested as a better sign of obstructive sleep apnoea than other clinical indices, ${ }^{67}$ and may be up to $77 \%$ sensitive and $82 \%$ specific for obstructive sleep apnoea in patients referred to a sleep clinic. ${ }^{6}$ These studies depend on retrospective data analysis, and the statistical veracity of the relation between neck circumference and general obesity has been questioned. ${ }^{8}$ So far there has been no prospective examination of this relationship. Furthermore, combining neck circumference with other features of sleep apnoea might further increase its sensitivity and specificity, allowing the clinical diagnosis to be made with reasonable confidence. This study examines these issues.

\section{Methods}

The study consisted of two parts. In the first the symptoms and signs present in 150 subjects being investigated for possible obstructive sleep apnoea were documented and the data retrospectively analysed to identify those features that independently predicted the severity of obstructive sleep apnoea. The regression model derived from this analysis was then prospectively tested in a further 85 subjects.

SUBJECTS

The study group consisted of consecutive patients having polysomnography to identify snoring and possible sleep apnoea (table 1). Of 
Table 2 Pearson's correlation coefficient analysis for the anthropometric variables

\begin{tabular}{|c|c|c|c|c|}
\hline & $\begin{array}{l}\text { Body mass } \\
\text { index }\end{array}$ & $\begin{array}{l}\text { Height corrected } \\
\text { neck circumference }\end{array}$ & $\begin{array}{l}\text { Neck } \\
\text { circumference }\end{array}$ & \\
\hline \multicolumn{5}{|l|}{ (a) Retrospective study } \\
\hline Saturation dip rate & $\begin{array}{l}0.47 \\
0.33-0.59 \\
p<0.0001\end{array}$ & $\begin{array}{l}0.59 \\
0.47-0.69 \\
p<0.0001\end{array}$ & $\begin{array}{l}0.58 \\
0.46-0.68 \\
p<0.0001\end{array}$ & $\begin{array}{l}\text { Correlation } \\
95 \% \text { CI } \\
\text { Significance }\end{array}$ \\
\hline Neck circumference & $\begin{array}{l}0.63 \\
0.52-0.72 \\
p<0.0001\end{array}$ & $\begin{array}{l}0.99 \\
0.98-0.99 \\
p<0.0001\end{array}$ & & \\
\hline Height corrected neck circumference & $\begin{array}{l}0.67 \\
0.57-0.75 \\
p<0.0001\end{array}$ & & & \\
\hline \multicolumn{5}{|l|}{ (b) Prospective study } \\
\hline Saturation dip rate & $\begin{array}{l}0.55 \\
0.32-0.68 \\
p<0.0001\end{array}$ & $\begin{array}{l}0.62 \\
0.47-0.74 \\
p<0.0001\end{array}$ & $\begin{array}{l}0.61 \\
0.46-0.73 \\
p<0.0001\end{array}$ & $\begin{array}{l}\text { Correlation } \\
95 \% \text { CI } \\
\text { Significance }\end{array}$ \\
\hline Neck circumference & $\begin{array}{l}0.84 \\
0.76-0.89 \\
p<0.0001\end{array}$ & $\begin{array}{l}0.99 \\
0.98-0.99 \\
p<0.0001\end{array}$ & & \\
\hline Height corrected neck circumference & $\begin{array}{l}0.86 \\
0.79-0.91 \\
\text { p }<0.0001\end{array}$ & & & \\
\hline
\end{tabular}

the prospective study group, $58 \%$ were referred directly from general practice, $21 \%$ from ear, nose, and throat departments, and $21 \%$ from other sources.

\section{CLINICAL ASSESSMENT}

During routine clinical assessment patients were weighed (with one set of lever balance scales, ABV 3306, Avery Ltd) and had their height measured (with a wall fixed height rule). Neck circumference was measured at the level of the cricothyroid membrane, with a correction for height based on a previously reported relationship, ${ }^{16}$ to produce a percentage of the predicted normal neck circumference. Obesity was expressed as the body mass index $\left(\mathrm{kg} / \mathrm{m}^{2}\right) .{ }^{9}$ A questionnaire was administered by the authors (appendix 1), who also measured the patient's neck circumference. ${ }^{1}$ The questionnaire covered snoring, daytime sleepiness, nasal disease, smoking, alcohol intake, and symptoms of narcolepsy. Answers were limited to the four responses "never," "rarely," "sometimes," "often," except in the case of smoking and alcohol intake, for which we used numerical categories (nil, 1-5, 6-15, > 15 cigarettes/day; <10, 10-39, 40-70, >70 g alcohol/day). All the clinical indices were recorded before polysomnography.

\section{SLEEP STUDIES}

All subjects had full polysomnography, including electroencephalography, electro-occulography, chin electromyography, oronasal airflow, recording of ribcage and abdomen movement (Multi-Parameter Analysis Recorder 1/Medilog 9000 , or Multi-Parameter Analysis Recorder 2/Medilog 9200, Oxford Medical Instruments), arterial pulse oximetry (Biox 3700 (10)), and continuous audio-video recording. Sleep staging was initially automated according to standard criteria, ${ }^{11}$ with manual review as necessary. The polysomnograms were reviewed by a panel to identify the presence and degree of any obstructive sleep apnoea. For the statistical analyses the severity of obstructive sleep apnoea was quantified by computer as the number of dips in arterial oxygen saturation of more than $4 \%$ per hour of study $\left(\mathrm{SaO}_{2}\right.$ dip rate). ${ }^{12}$ This index correlates with the severity of obstructive sleep apnoea quantified in other

Table 3 Multiple linear regression modelling of the questionnaire and anthropometric retrospective data with $>4 \% \mathrm{SaO}_{2}$ dip rate as the dependent variable

\begin{tabular}{|c|c|c|c|c|}
\hline & Individual $r^{2}$ & Multiple $r^{2}$ & $\begin{array}{l}\text { \% variance } \\
\text { explained }\end{array}$ & Significance ( $p$ ) \\
\hline \multicolumn{5}{|l|}{ (a) Questionnaire variables alone } \\
\hline $\begin{array}{l}\text { Q5 Do you fall asleep when not busy? } \\
\text { Q7 Do you fall asleep against your will? } \\
\text { Q2 Do you have a problem related to sleeping? }\end{array}$ & $\begin{array}{l}0.13 \\
0.08 \\
0.04\end{array}$ & $\begin{array}{r}0.13 \\
<0.01 \\
<0.01\end{array}$ & $\begin{aligned} & 13 \% \\
<< & 1 \% \\
< & 1 \%\end{aligned}$ & $\begin{array}{l}<0 \cdot 001 \\
\text { NS } \\
\text { NS }\end{array}$ \\
\hline \multicolumn{5}{|l|}{ (b) Anthropometric variables alone } \\
\hline $\begin{array}{l}\text { Height corrected neck circumference } \\
\text { Body mass index }\end{array}$ & $\begin{array}{l}0.35 \\
0.22\end{array}$ & $\begin{array}{l}0.35 \\
0.01\end{array}$ & $\begin{array}{r}35 \% \\
1 \%\end{array}$ & $\begin{array}{l}<0.0001 \\
\text { NS }\end{array}$ \\
\hline \multicolumn{5}{|c|}{ (c) Independent correlates derived from models $A$ and $B$ together } \\
\hline $\begin{array}{l}\text { Height corrected neck circumference } \\
\text { Q5 Do you fall asleep when not busy? }\end{array}$ & $\begin{array}{l}0.35 \\
0.13\end{array}$ & $\begin{array}{l}0.35 \\
0.01\end{array}$ & $\begin{array}{r}35 \% \\
1 \%\end{array}$ & $\begin{array}{l}<0.0001 \\
\text { NS }\end{array}$ \\
\hline
\end{tabular}

Regression relationship for the single independent correlate of saturation dip rate: 
Table 4 Multiple linear regression of the prospective anthropometric data set (analysis performed exactly as in the retrospective study)

\begin{tabular}{|c|c|c|c|c|}
\hline & Individual $r^{2}$ & Multiple $r^{2}$ & $\begin{array}{l}\% \text { variance } \\
\text { explained }\end{array}$ & Significance ( $p)$ \\
\hline $\begin{array}{l}\text { Height corrected neck circumference } \\
\text { Body mass index }\end{array}$ & $\begin{array}{l}0 \cdot 38 \\
0 \cdot 30\end{array}$ & $\begin{array}{r}0.38 \\
<0.01\end{array}$ & $\begin{array}{r}38 \% \\
<1 \%\end{array}$ & $\begin{array}{l}<0.0001 \\
\text { NS }\end{array}$ \\
\hline
\end{tabular}

$\mathrm{SaO}_{2}$-arterial oxygen saturation.

ways, ${ }^{13-15}$ and being determined by computer it is free from observer bias.

\section{STATISTICAL ANALYSIS}

Statistical analysis used the SAS suite of programs (SAS Institute Inc, Cary, North Carolina).

\section{Retrospective study}

Pearson's correlation coefficients were calculated for $\mathrm{SaO}_{2}$ dip rate, percentage of predicted neck circumference, and obesity index (table 2). Analysis of variance was used to correlate the categorical questionnaire data with $\mathrm{SaO}_{2}$ dip rate; significant results were rejected unless the answer rates progressed logically through the response categories. Those variables that correlated with $\mathrm{SaO}_{2}$ dip rate in these analyses were entered into multiple linear regression models (ordered according to their individual correlations with $\mathrm{SaO}_{2}$ dip rate as the dependent variable). For the categorical data analysis the general linear models procedure with the classes option was used. ${ }^{16}$ Initially the questionnaire variables were analysed alone (table $3 a$ ), as were the anthropometric variables (table $3 b$ ). This identified one independent questionnaire predictor of $\mathrm{SaO}_{2}$ dip rate and one independent anthropometric predictor, which were modelled together in a third analysis (table $3 c$ ). For retention in these models $p$ had to be below $<0 \cdot 15$. This final regression model (table $3 c$ ) was expressed graphically (figure).

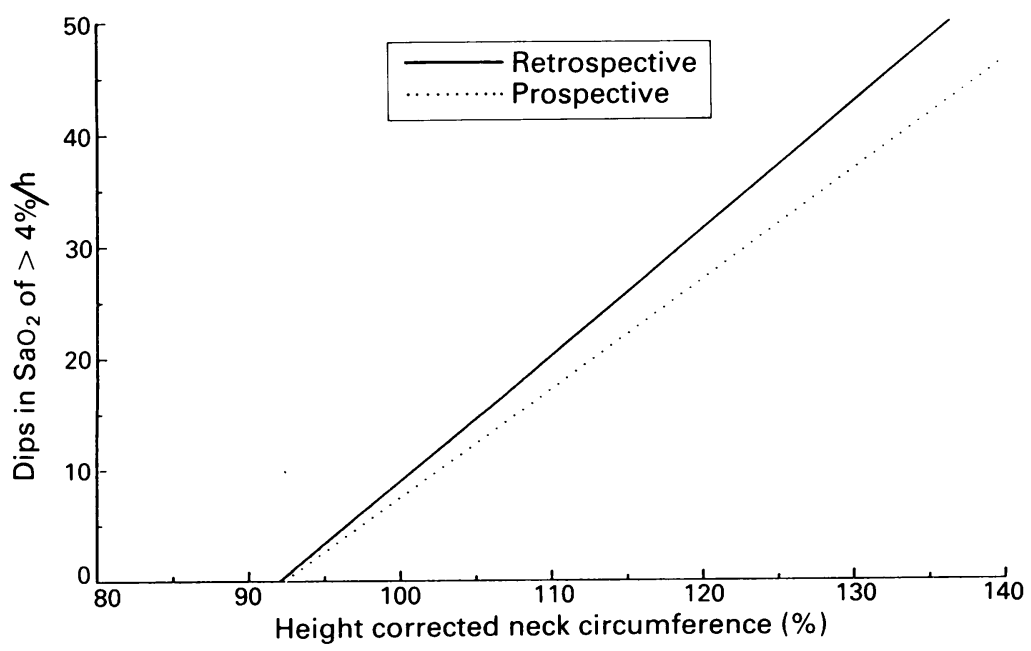

Graph showing the relation between height corrected neck circumference and number of dips of more than $4 \%$ in arterial oxygen saturation $\left(\mathrm{SaO}_{2}\right)$ per hour for both the retrospective and the prospective data sets.
Prospective study

As the questionnaire variables did not explain more than $13 \%$ of the variance in $\mathrm{SaO}_{2}$ dip rate, and did not improve the anthropometric regression model (table 3 ), we limited our prospective study to anthropometric variables. Percentage of predicted neck circumference and body mass index were determined in 85 new subjects and modelled to explain variance in $\mathrm{SaO}_{2}$ dip rate exactly as they had been in the retrospective analysis (table 4 ). The resulting regression equation was expressed graphically (figure) and statistically compared for gradient and vertical difference with the retrospective model. ${ }^{17}$

\section{Results}

\section{RETROSPECTIVE ANALYSIS}

Percentage of predicted neck circumference, body mass index (table 2), and the answers to the following three questions individually correlated with $\mathrm{SaO}_{2}$ dip rate:

Q2 Do you think you have a problem related to sleeping? $(p<0.03)$

Q5 Do you fall asleep during the day, particularly when not busy? $(\mathrm{p}<0.001)$

Q7 Do you ever fall asleep during the day against your will? $(p<0.01)$

All the variance in $\mathrm{SaO}_{2}$ dip rate explained by the answers to questions 2 and 7 was explained by question 5 alone (table $3 a$ ). All the variance in $\mathrm{SaO}_{2}$ dip rate explained by body mass index was explained by percentage of predicted neck circumference (table $3 b$ ). Question 5 does not improve the amount of variance explained by percentage of predicted neck circumference alone (table $3 c$ ).

If the order in which the variables were entered into the models is changed, question 5 significantly increases the amount of variance explained by questions 2 and 7 together, and in both study groups percentage of predicted neck circumference significantly increased the amount of variance explained by body mass index.

PROSPECTIVE ANALYSIS

In this data set the individual Pearson correlation coefficients between $\mathrm{SaO}_{2}$ dip rate, body mass index, and percentage of predicted neck circumference were similar to those from the retrospective data set (table 2 ). The retrospective and prospective models were not significantly different in either gradients or vertical separations (figure). 


\section{Discussion}

This study examines the interrelationships between the symptoms and signs of obstructive sleep apnoea in patients referred to a sleep clinic. There have been similar studies, ${ }^{671819}$ but none has combined neck circumference, general obesity and symptoms, or tested the conclusions prospectively. Such analyses are helpful because physicians without immediate access to facilities for sleep studies depend on clinical features to raise their suspicion of the disease. This study has prospectively confirmed that the relation between obstructive sleep apnoea severity and general body obesity is dependent on variation in neck circumference.

As the subjects for this analysis have been drawn from a specialist sleep clinic the exact correlations observed will differ from those in less selected populations. ${ }^{1}$ Most of the patients studied, however, had been directly referred from general practice and the relation between neck circumference corrected for height and the severity of nocturnal hypoxaemia has been observed in an unselected community population. ${ }^{1}$ Thus the conclusion that neck circumference is a better clinical predictor of obstructive sleep apnoea than is general body obesity may be extended to wider populations with some confidence.

Neck circumference has been corrected for height ${ }^{16}$ as this significantly increases the amount of variance in $\mathrm{SaO}_{2}$ dip rate it explains during linear regression analysis. In clinical practice this correction produces only a small improvement in usefulness. Applying the retrospectively derived definitions of significant obstructive sleep apnoea and an increased percentage of predicted neck circumference as reported elsewhere $\left(\mathrm{SaO}_{2}\right.$ dip rate over 10 per hour and percentage of predicted neck circumference above the 105 th centile), ${ }^{6}$ to the prospective data set shows a neck circumference above $105 \%$ of the predicted value to be $87 \%$ sensitive and $79 \%$ specific, with a positive predictive value of $66 \%$ for significant obstructive sleep apnoea. (105\% represents a 16.75 inch neck $(42.5 \mathrm{~cm})$ neck circumference in a $5 \mathrm{ft} 10$ inch $(1.78 \mathrm{~m})$ man.) In the prospective study group the uncorrected measure is $92 \%$ sensitive, and $73 \%$ specific, with a positive predictive value of $57 \%$ for significant obstructive sleep apnoea defined in the same way. As these figures result from a prospective analysis using predetermined diagnostic criteria they are likely to represent the true clinical usefulness of this sign in the sleep clinic setting (though differing patterns of referral to other clinics may result in minor variations). Thus neck circumference is a more useful clinical predictor of obstructive sleep apnoea than are classical signs and symptoms, though alone it is not an adequate index for the diagnosis and formal sleep studies remain necessary. This questionnaire does not ask whether the patient's partner has seen episodes of nocturnal apnoea, found to be a predictor of obstructive sleep apnoea at polysomnography. ${ }^{18}$ Possibly the combination of height corrected neck circumference with this feature would further improve its usefulness.
In this study the questionnaire variable regression model explains only $13 \%$ of the variance in $\mathrm{SaO}_{2}$ dip rate. This shows the classical hallmarks of obstructive sleep apnoea (snoring and daytime sleepiness) to be of limited use in patients referred to a sleep clinic population. Similar observations have been made by others. ${ }^{1819}$ This may be for several reasons. Firstly, those patients referred for assessment of sleep and breathing disorders are frequently snorers with a history of daytime sleepiness. In this study $96 \%$ reported that they snored sometimes or often and $91 \%$ answered "sometimes" or "often" to at least one question relating to daytime sleepiness. This high prevalance inevitably degrades the specificity of symptoms for sleep apnoea. ${ }^{20}$ In effect, what specificity these symptoms possess has been exploited during the referral process. Secondly, hypersomnolence in those who snore is probably not always due to obstructive apnoea. Snoring itself, even in the absence of 웅 frank respiratory obstruction, may be associated with symptomatic daytime sleepiness and subtle disruption of sleep. ${ }^{21} 22$

The correlation between neck size and $\mathrm{SaO}_{2}$ dip rate is not improved by the addition to the model of symptoms of obstructive sleep apnoea, and the variance in $\mathrm{SaO}_{2}$ dip rate that can be predicted from daytime sleepiness appears to be secondary to variation in neck circumference. As daytime sleepiness occurs as a consequence of night time pharyngeal collapse (and thus of apnoea causing sleep disruption) this constitutes indirect support for the argument that fat deposition in the neck, ${ }^{6}$ through mass loading of the pharynx, ${ }^{53}$ provokes obstructive sleep apnoea in most adult cases.

In conclusion, this study confirms the previously debated finding that the variance in the severity of obstructive sleep apnoea explicable by body mass index depends on variation in neck circumference. It shows that the classical symptoms and signs of obstructive sleep apnoea are of little diagnostic help in the patients referred to a sleep clinic and indicates that neck circumference corrected for height is a reproducible and a helpful clinical predictor. Alone, however, this is insufficiently sensitive or specific to circumvent the need for sleep studies in the diagnosis of this disease.

RJOD is supported by a Wellcome graduate research fellowship, NJA by funds from the British Lung Foundation, and JRS by a Wellcome senior research fellowship.

\section{Appendix: The questionnaire}

1 What is your job? Does it involve shift work? (Yes No)

2 Do you have a problem related to sleeping?

3 Do you have difficulty getting to or staying asleep?

4 Do you get chronic sleepiness, fatigue, or weariness that you can't explain?

5 Do you fall asleep during the day, particularly when you are not busy?

6 Do you fall asleep reading or watching television?

7 Do you fall asleep during the day against your will?

8 Do you take a planned daytime nap?

9 Do you think you might have ever had a car accident through sleepiness?

10 Have you almost had an accident while driving due to sleepiness? 
11 Do you have to pull off the road while driving due to sleepiness?

12 Have you ever had a bad accident at work or in your home?

13 How long do you estimate you sleep altogether per 24 hours?

14 Do you ever have sudden attacks of muscle weakness or falling?

15 As you fall asleep do you have strange or frightening dreams?

16 As you fall asleep, or wake up, do you ever feel paralysed for a few moments?

17 Are you a restless sleeper, or have you been told you move your arms and legs a lot while asleep?

18 Do you get choking or shortness of breath feelings at night?

19 Do you snore, or have you been told you do?

20 When did your snoring start?

21 Do you get morning fatigue, fogginess or wake up unrefreshed?

22 Do you wake up during sleep?

23 Do you ever wake up with headaches?

24 Do you get stiffness or aching in your body when you wake?

25 Roughly how much alcohol do you drink in a day?

26 Do you smoke cigarettes?

27 Do you get a stuffy or blocked nose?

28 Have you ever damaged your nose, or had surgery to it?

29 Have you had your tonsils out?

30 Do you take tranquilisers or sleeping tablets?

1 Stradling JR, Crosby JH. Predictors and prevalence of obstructive sleep apnoea and snoring in 1001 middle aged men. Thorax 1991;46:85-90.

2 Guilleminault C, Tilkian A, Dement WC. The sleep apnoea syndromes. Annu Rev Med 1976;27:465-84.

3 Findley L, Unverstadt M, Surratt P. Automobile accidents in patients with obstructive sleep apnoea. Am Rev Respir Dis 1988;138:337-40.

4 George C, Nickerson P, Hanly P, Millar T, Kryger M. Sleep apnoea patients have more automobile accidents. Lancet 1987;ii:447.

5 Hapnonik EF, Smith PL, Meyers DA, Bleecker ER. Evalua- tion of sleep disordered breathing, is polysomnography necessary? Am J Med 1984;77:671-7.

6 Davies RJO, Stradling JR. The relationship between neck circumference, radiographic pharyngeal anatomy, and the obstructive sleep apnoea syndrome. Eur Respir J 1990;3:509-14.

7 Katz I, Stradling JR, Slutsky AS, Zamel N, Hoffstein V. Do patients with obstructive sleep apnoea have a thick neck? Am Rev Respir Dis 1990;141:1228-31.

8 Partinen $M$. Body mass index and neck circumference in obstructive sleep apnoea. Am Rev Respir Dis 1991; 143:204.

9 Revicki DA, Israel RG. Relationship between body mass indices and measures of adiposity. Am J Publ Health 1986;76:992-4

10 Warley ARH, Stradling JR, Mitchell J. Evaluation of Ohmeda 3700 pulse oximeter. Thorax 1987;42:892-896.

11 Rechtschaffen A, Kales A. A manual of standardised terminology, techniques and scoring system for sleep stages of human
subjects. Washington DC: Public Health Service, 1968. subjects. Washington DC: Public Health Service,
(National Institutes of Health publication No 204.)

12 Stradling JR, Crosby JH. Relation between systemic hypertension and sleep hypoxaemia or snoring: analysis in 748 men drawn from general practice. $B M J$ 1990;300:75-8.

13 Farney RJ, Walker LE, Jensen RL, Walker JM. Ear oximetry to detect apnea and differentiate rapid-eye movement (REM) and nonREM sleep. Chest 1988; 89:533-9.

14 George CF, Millar TW, Kryger MH. Identification and quantification of apneas by computer based analysis of oxygen saturation. Am Rev Respir Dis 1988;137:1238-40.

15 Gould GA, Whyte KF, Airlie MAA, Rhind GB, Catterall JR, Shapiro CM, et al. Criteria for diagnosing abnormal breathing during sleep [abstract]. Thorax 1987;42:722.

16 Cody RP, Smith JK. Applied statistics and the $S A S$ programming language. 2nd ed. New York: Elsevier, 1987.

17 Gardner MJ, Altman DG, eds. Statistics with confidence. London: British Medical Journal, 1989.

18 Crocker BD, Olson LG, Saunders NA, Hensley MJ, Mckeon JL, Allen KM, et al. Estimation of the probability of disturbed breathing during sleep before a sleep study. Am Rev Respir Dis 1990;142:14-8.

19 Allen MB, Douglas NJ. Is a symptom based questionnaire useful in the diagnosis of the sleep apnoea/hypopnoea syndrome? Thorax 1990;45:789A.

20 Armitage P. Statistical methods in medical research. London: Blackwell, 1977:426-41.

21 Hoffstein V, Mateika JH, Mateika S. Snoring and sleep architecture. Am Rev Respir Dis 1991;143:92-6.

22 Guilleminault C, Stoohs R, Duncan S. Daytime sleepines in regular heavy snorers. Chest 1991;99:40-8.

23 Koenig JE, Thach BT. Effects of mass loading on the uppe airway. J Appl Physiol 1988;64:2294-9. 